\title{
X-ray diffraction analysis of a sintered product made of electroerosive chromium-containing powder
}

\author{
S.V. Khardikov ${ }^{1, *}$, E.V. Ageeva ${ }^{1}$, V.I. Serebrovsky ${ }^{2}$, and V.I. Kolmykov ${ }^{1}$ \\ ${ }^{1}$ Southwest state University, 305040, Kursk, Russian Federation. \\ ${ }^{2}$ Kursk State Agricultural Academy, 305021, Kursk, Russian Federation.
}

\begin{abstract}
This article presents the results of x-ray diffraction analysis of a sintered sample made of X13 alloy electroerosive materials obtained in butyl alcohol. It was found that in the sintered sample by the method of spark plasma sintering from alloy $\mathrm{X} 13$, the main phases are $\mathrm{Fe}, \mathrm{Cr}$, and $\mathrm{FeNi}_{3}$.
\end{abstract}

\section{Introduction}

Structural powder steels are sintered materials used to replace cast and forged steels in the manufacture of machine parts and apparatus using powder metallurgy methods.

Powder steels are based on iron, the properties of which during sintering have a great influence on the formation of the structure and properties of steel. Along with powder steels, powder products can be made on the basis of one iron powder, as well as iron alloyed with other elements.

Powder technology is a wide area for the production of dispersed bodies used in various industries - powder metallurgy, ceramic industry, production of food and medicinal products, fertilizers, fuel, building materials, etc. , manufactured by powder metallurgy methods, are also widely known as cermet [1-4].

Along with the advantages of powder metallurgy, it should be noted the disadvantages that complicate and limit its widespread use. The main disadvantages include the high cost of metal powders and the lack of mastered methods of obtaining alloy powders - steels, bronzes, brass, etc. One of the options for solving these problems is the use of electrical erosion. Currently, alloyed steels and alloys containing a significant amount of non-ferrous metals are used for the manufacture of critical parts for various purposes, since it is alloyed steels and alloys that have a complex of high physical, mechanical and other properties.

Carbon steels do not have sufficiently high mechanical and physicochemical properties and do not meet the requirements for metals in modern mechanical engineering. One of the main ways to improve the properties of steel is to introduce various elements into it. The process of introducing various elements into steel that enhance its properties is called alloying, and the resulting steels are called alloyed [5-8].

\footnotetext{
* Corresponding author: hardikov1990@mail.ru
} 
The introduction of alloying elements leads to the formation of new phases and structural components, changes the kinetics of transformations, causes new phenomena and changes the technology of heat treatment. Alloying elements introduced into carbon steel change its mechanical and physical properties. Alloying significantly increases the strength and hardness while maintaining good toughness of steel, increases its hardenability, and allows quenching in moderate coolants. Alloying gives steels a number of special properties: heat resistance, corrosion resistance, scale resistance, magnetic resistance and many other properties.

Chromium is the most common alloying element. Steel alloyed with chromium has increased strength, hardness, and wear resistance, corrosion resistance in aggressive and oxidizing environments. The presence of chromium increases the hardenability of the steel. When steel contains $13 \%$ chromium, it becomes stainless. A further increase in the chromium content imparts anticorrosion resistance to steel at high temperatures, as well as magnetoresistance [9-14].

To develop technologies for the reuse of electroerosive powders and assess the effectiveness of their use, complex theoretical and experimental studies are required.

The aim of the work was to carry out X-ray diffraction analysis of sintered samples from electroerosive chromium-containing powders obtained by the method of electroerosive dispersion in butyl alcohol.

\section{Materials and Methods}

To carry out the planned studies, X13 steel wastes were chosen as the dispersible material, which accumulate in large volumes at enterprises.

Waste steel X13 was processed on an electrodispersion unit. The electrodispersion process was carried out under the following conditions: voltage $90 \ldots 100 \mathrm{~V}$; pulse repetition rate $100 \ldots 110 \mathrm{~Hz}$; capacity $48 \mathrm{uF}$. Butyl alcohol was used as a working fluid.

Consolidation of the obtained powder was carried out by the method of spark plasma sintering (IPA) using a spark plasma sintering system SPS 25-10 (Thermal Technology, USA).

To study the structure of particles of the obtained powder materials, their X-ray structural analysis was carried out on an X-ray diffractometer Rigaku Ultima IV.

High-resolution diffractometer "Ultima IV" Rigaku with a cobalt anode for precise determination of the qualitative and quantitative phase composition of polycrystalline and ceramic materials, including those with a high iron content.

The Ultima IV is the only diffractometer with a fully automatic alignment of the entire X-ray optical system. Owing to the ability to automatically adjust the system in combination with CBO optics and in-plane geometry, this diffractometer is the most flexible system available for solving a wide range of applied problems. CBO optics can significantly reduce the time spent in the transition from one measurement geometry to another, allows the daily use of both geometries without the need to reconfigure the system, is not subject to wear and tear as a result of multiple switchings. CBO optics and automatic alignment, combined together, provide maximum functionality for powder diffractometry, thin film diffractometry, small angle scattering, and in-plane scattering.

Features:

The main advantage of the Ultima IV diffractometric complex is a wide range of combinations of elements of the rantgeno-optical system due to the use of the SVO technology. As a result, the user gets the following modes: Focusing, Parallel, High resolution, SAXS and, finally, MicroArea.

According to applicability, these modes are distributed as follows: 
Focusing mode - identification of phase composition, determination of crystallite sizes, determination of material crystallinity in percent;

Combination of Focusing / Parallel beam modes - determination of surface relief, residual stresses of the material, size distribution of nanoparticles / nanopores, conventional diffraction;

Parallel beam mode - determination of the thickness and density of films, certification of epitaxial films, certification of ultrathin films;

The second unique technology used in the Ultima IV is the fully automatic alignment, which adjusts the X-ray source height position, incident beam direction, focusing mirror tilt, slit size, zero point for $2 \theta$, and detector modes. After this automatic setup, the user gets what is commonly called the ideal signal (see figure):

The next promising technology used in the Ultima IV is the automatic diffractometer configuration, in which the device itself recognizes the connected devices and optional addons (the figure shows a typical window for automatic recognition and system configuration):

Thus, the time spent by the user on preparing the system for measurements is significantly saved.

The powder material of the test sample is poured into a cuvette, which has the following overall dimensions: diameter $20 \mathrm{~mm}$, depth $0.5 \mathrm{~mm}$. Then they are compressed. In this case, the parallelism of the edges of the cuvette with the sample surface is necessary. Then, the cuvette is placed in the holder. This is done in order to align the focusing plane with the sample surface. [15-20].

\section{Results}

The results of the X-ray diffraction analysis of powder materials obtained by the EED method from waste steel grade X13 are presented in Figure 1 and Table 1.

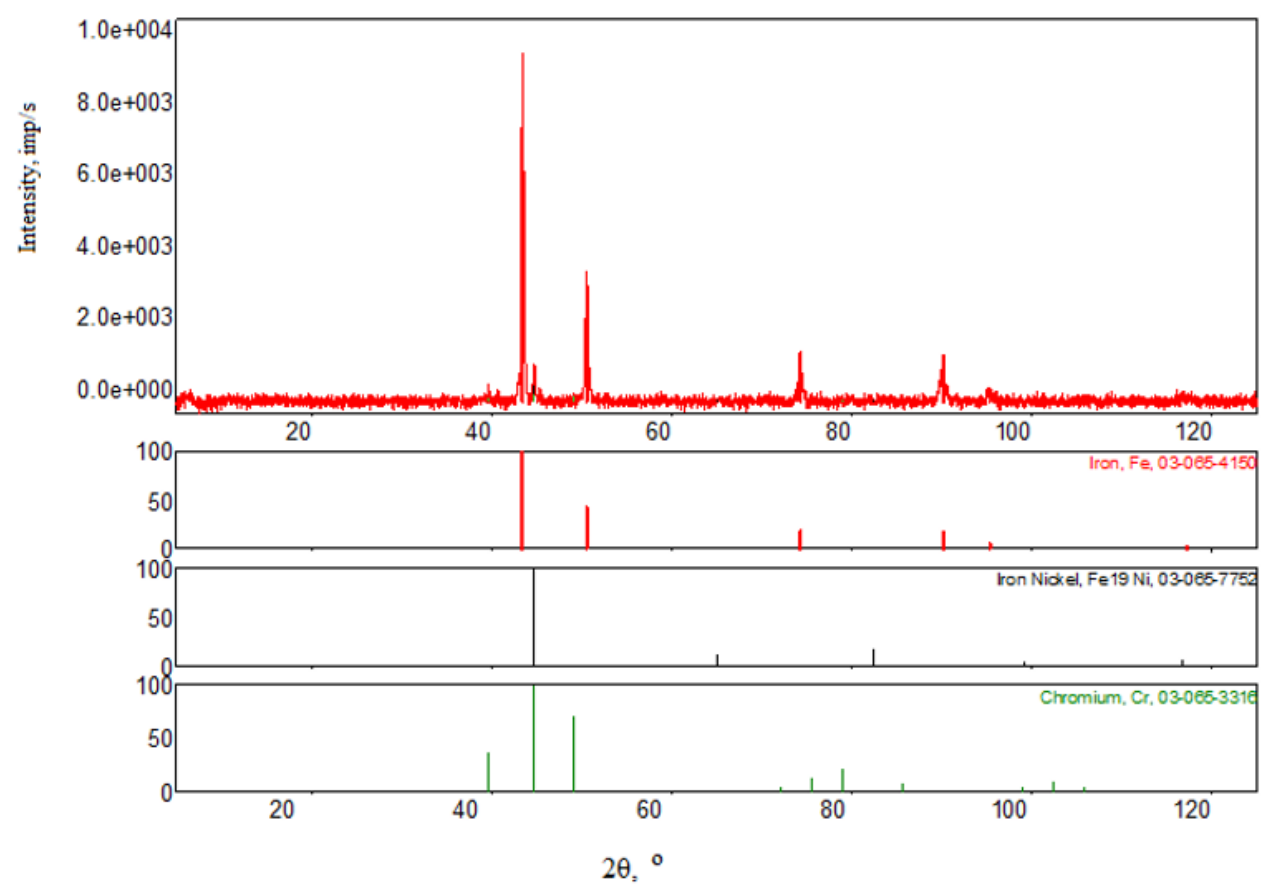

Fig. 1. X-ray of a sintered sample 
Table 1. Phase composition of the sintered sample

\begin{tabular}{|c|c|c|c|}
\hline \multirow{2}{*}{ Parameter } & \multicolumn{3}{|c|}{ Phase name } \\
\cline { 2 - 4 } & Iron (Fe) & Chromium (Cr) & $\begin{array}{c}\text { Iron Nickel } \\
\left(\mathrm{FeNi}_{3}\right)\end{array}$ \\
\hline Crystal lattice type & $\begin{array}{c}\text { cubic crystal } \\
\text { lattice }\end{array}$ & cubic crystal lattice & $\begin{array}{c}\text { cubic crystal } \\
\text { lattice }\end{array}$ \\
\hline $\begin{array}{c}\text { Crystal lattice } \\
\text { parameters, } \AA\end{array}$ & $\begin{array}{c}\mathrm{a}=\mathrm{b}=\mathrm{c}= \\
\mathrm{n}\end{array}$ & $\mathrm{a}=\mathrm{b}=\mathrm{c}=$ & $\mathrm{a}=\mathrm{b}=\mathrm{c}=$ \\
$2.609732 \AA$ & $2.862071 \AA$ & $4.531833 \AA$ \\
\hline
\end{tabular}

Experimental radiographs show strong reflections corresponding to:

- phase Fe;

- phase Cr;

- phase $\mathrm{FeNi}_{3}$.

It was experimentally established that in a sintered sample, from electroerosive chromium-containing powders obtained in butyl alcohol, the main phases in the sintered samples are $\mathrm{Fe}, \mathrm{Cr}$ and $\mathrm{FeNi}_{3}$.

\section{Conclusion}

In the course of the study, it was found that in the sintered sample by the method of spark plasma sintering from alloy $\mathrm{X} 13$, the main phases are $\mathrm{Fe}, \mathrm{Cr}$ and $\mathrm{FeNi}_{3}$. On the basis of experimental studies of sintered specimens from electroerosive high-chromium powders obtained in butyl alcohol, the high efficiency of the use of spark plasma sintering technology was shown, which provides, with a short operating cycle time and suppression of grain growth, a uniform heat distribution over the specimen, controlled porosity and high physical and mechanical properties. properties.

The work was supported by a scholarship of the President of the Russian Federation for young scientists and graduate students (SP-945.2019.1).

\section{References}

[1] A.A. Lipatov, RER, 33, 3, 144-149 (2013)

[2] S.B. Maslenkov, All materials. Encyclopedic Reference 1, 18 (2007).

[3] V.A. Falkowski, F.I. Falkowski, V.S. Panov, Non-Ferrous Metal. 10, 85 (2007).

[4] E.V. Azarova, E.A. Levashov, V.G. Ralchenko, A.P. Bolshakov, E.E. Ashkinazi, Metall., 54, 523-529 (2010)

[5] Z. Qiao, X. Ma, W. Zhao, H. Tang, B. Zhao, J. of All. and Comp., 462, 416-420 (2008)

[6] K. Maruyama, T. Nonaka, H.Y. Kim, Intermet., 13, 1116-1121 (2005)

[7] E.V. Ageev Patent 2449859, Russian Federation, C2, B22F9 / 14. Installation for producing nanodispersed powders from conductive materials, applicant and patent holder Southwestern State University. - No. 2010104316/02; application 02/08/2010; publ. 05/10/2012, 4.

[8] E.V. Ageev, E.V. Ageeva, Bull. of mech.eng., 11, 51-57 (2013)

[9] E.V. Ageev, B. A. Semenikhin, R. A. Latypov, Fund. Prikl. Probl. Tekhn. Tekhn., 5, 39-42 (2010) 
[10] T.N. Oskolkova, E.A. Budovskikh, Metal. Sci. Heat Treat, 55, 96-99 (2013)

[11] J. Karlsson, A. Snis, H. Engqvist, J. Lausmaa, J. of Mat. Proc. Techn., 213, 21092118 (2013)

[12] D.D. Gu, W. Meiners, K. Wissenbach, R. Poprawe, IMR, 57, 133-164 (2012)

[13] N. Radek, Maint. and Rel., 4, 10-16 (2009)

[14] A.V. Ribalko, O. Sahin, Surf. \& Coat.Techn., 168, 129-135 (2003)

[15] Z. Chen, Y. Zhou, Surf. \& Coat.Techn, 201, 1503-1510 (2006)

[16] I.V. Galinov, R.B. Luban, Surf. \& Coat.Techn, 79, 9-18 (1996)

[17] E.V. Azarova, E.A. Levashov, V.G. Ralchenko, Transl. from Metall. 8, 50-55 (2010)

[18] A. Pereverzev., E. Ageev., MATEC Web of Conf., 298, 00037 (2019)

[19] E.V. Ageev, S.V. Khardikov, E.A. Vorobyev, A.A. Sysoev, MATEC Web of Conf., 298, 00127 (2019)

[20] R.A. Latypov, E.V. Ageeva, G.R. Latypova, MATEC Web of Conf., 298, 00125 (2019) 